\title{
Desigualdade no início do século XXI: o Brasil na contramão mundial?
}

\author{
Inequality at the beginning of the XXI century: Brazil going the "wrong" way?
}

Ana Luíza Matos de OLIVEIRA*

https://orcid.org/0000-0002-9623-3305

Resumo: No início do século XXI, o Brasil parecia caminhar na contramão mundial, ao experimentar uma redução, enquanto os países desenvolvidos experimentavam um crescimento da desigualdade. Neste artigo, discute-se em que medida esse processo de redução das desigualdades ocorreu no início do século XXI (até 2015, pelo menos) e se foi capaz de contrastar com a desigualdade estruturante da sociedade brasileira. Se não há consenso entre os autores - devido a diferentes metodologias adotadas - quanto à queda da desigualdade de renda no período, a literatura indica queda da desigualdade relativa ao acesso a direitos sociais. No entanto, após 2015, a redução das desigualdades - até mesmo no acesso a direitos parece estar em risco, colocando em questão a real profundidade do processo vivido durante o início do século.

Palavras-chave: Desigualdade. Brasil. Direitos sociais. Século XXI. Social-desenvolvimentismo.

Abstract: At the beginning of the 21st century, Brazil seemed to be going the "wrong" way compared to the world by experiencing a reduction in inequality, while developed countries experienced a growth. In this article, we discuss the extent to which this process really occurred at the beginning of the 21st century (until 2015, at least) and to see if we were able to contrast this with the structural inequality in Brazilian society. Even though there is no consensus among authors - due to different methodologies adopted regarding the fall in income inequality in the period, the literature indicates a drop in inequality related to access to social rights. However, after 2015 the reduction of inequalities - even in access to rights seems to be at risk, calling into question the real depth of the process experienced at the beginning of the century.

Keywords: Inequality. Brazil. Social Rights. XXI century. Social-Developmentalism.

Submetido em: 16/5/2019. Aceito em: 4/11/2019.

\section{INTRODUÇÃO}

$\mathrm{N}$ o início do século XXI, o Brasil parecia caminhar na contramão mundial ao reduzir a desigualdade, enquanto outros países - inclusive os ditos desenvolvidos - experimentavam um crescimento dessa. O fenômeno chama a atenção de diversos especialistas, dado que o Brasil é um dos países mais desiguais do mundo.

\footnotetext{
* Economista. Doutora em Desenvolvimento Econômico. Professora visitante da FLACSO Brasil. Avenida Ipiranga, $\mathrm{n}^{\mathrm{0}}$ 1.071, sala 608, República, São Paulo (SP). E-mail: <almatosdeoliveira@gmail.com>.
}

$(\mathrm{cc}) \mathrm{BY}$

(s) Autora(s)/O(s) Autor(es). 2019 Acesso Aberto Esta obra está licenciada sob os termos da Licenç Creative Commons Atribuição 4.0 Internacional (https://creativecommons.org/licenses/by/4.o/deed.pt_BR), que permite copiar e redistribuir o material em qualquer suporte ou formato, bem como adaptar, transformar e criar a partir deste material para qualquer fim, mesmo que comercial. O licenciante não pode revogar estes direitos desde que você respeite os termos da licença. 
Neste artigo, busca-se discutir em que medida esse processo de redução das desigualdades ocorreu no início do século XXI (até 2015, pelo menos) e se foi capaz de contrastar com a desigualdade estruturante da sociedade brasileira. A escolha desse período é baseada em Fagnani (2017), que aponta que, entre 196o e 1980, o Brasil passou por um período que combinava crescimento econômico e crescimento da desigualdade (coincidente, em linhas gerais, com o período da Ditadura Militar). De 1980 a 2001, o país passou por uma estagnação da economia e estabilização do coeficiente de Gini, para, de 2001 a 2015, retomar o crescimento econômico e reduzir o coeficiente de Gini. Assim, no início do século XXI, segundo Fagnani (2017), teria ocorrido um crescimento da economia com a diminuição das desigualdades e uma melhoria dos indicadores sociais e do mercado de trabalho, o que parte da literatura chama de social-desenvolvimentismo (CARNEIRO, 2012).

A fim de organizar a abordagem do tema, o artigo se estrutura da seguinte maneira: 1) uma seção que discute as diversas formas de medir a desigualdade; 2) uma seção que discute a desigualdade como questão estruturante da sociedade brasileira; e 3) uma seção que revisa a literatura sobre desigualdade no início do século XXI no Brasil.

\section{Como medir a desigualdade}

Pochmann (2017) enumera três dimensões em que se manifestam as desigualdades na vida em sociedade: na dimensão do ter (recursos materiais), na dimensão do poder (recursos sociais e políticos) e na dimensão do saber (recursos do conhecimento). É raro que metodologias consigam analisar as três dimensões simultaneamente, e, quando não o fazem, a compreensão sobre as determinações, dimensões, relações e combinações relativas à desigualdade podem ficar obscuras. Essa dificuldade e os problemas de imperfeições de dados utilizados resultam em análises limitadas e frágeis e na adoção de instrumentos de combate às desigualdades não só insuficientes, mas também contraproducentes (POCHMANN, 2017).

Entretanto, várias são as formas de medir a desigualdade, que dependem da existência de dados e do acesso a eles: uma delas, estabelecida em 1914 e uma das mais empregadas, é o Índice de Gini, que mede a concentração da renda (primária, determinada pelo mercado, ou líquida, após a presença de tributos e subsídios) em uma sociedade; outra forma é considerar a repartição da renda de acordo com percentil, decil, quintil ou quartil; há ainda a que afere a concentração da riqueza sem considerar a renda ou o consumo; e também a que mede pela participação da massa salarial na renda nacional.

Além desses procedimentos citados, há índices multidimensionais que consideram a repartição da renda e do acesso a direitos sociais ${ }^{1}$. Campello (2017), baseando-se na metodologia multidimensional do Banco Mundial, propõe uma análise sobre a desigualdade não em termos de renda, mas em termos de acesso a direitos sociais. Afinal, a análise da desigualdade de renda pode não incorporar uma parte expressiva do bemestar que não é comprado pelo mercado. Também há estudos, como Gibb e Oliveira

${ }^{1}$ Há ainda discussões de diversos autores sobre conceitos a serem usados, que envolvem, por exemplo, as diferenças entre equidade, igualdade e equivalência, como explicita Moreno (2007).

Argum., Vitória, v. 11, n. 3, p. 171-185, set./dez. 2019. | ISSN 2176-9575 
(2015), que enfocam a divisão do uso do tempo, que pode estar relacionada a fatores de preconceito e machismo, e influenciar trajetórias profissionais de acordo com o gênero.

Considera-se que a concepção de desigualdade não pode se restringir à renda, pois o acesso aos direitos sociais, sendo provido pelo governo ou não, tem impacto na renda disponível das famílias (DWECK; SILVEIRA; ROSSI, 2018; ROSSI; DWECK; OLIVEIRA, 2018). A partir de Pochmann (2017), se as discussões sobre desigualdade não incorporam outras dimensões relativas ao acesso aos direitos sociais, à política social e ao papel do Estado, intervenções para reduzi-la são necessariamente parciais.

Outro aspecto fundamental para analisar as desigualdades no capitalismo, além da análise da renda, são as diferenças geográficas e regionais, de gênero e cor/raça. Sobre a questão regional, Harvey (2011) chama atenção para o fato de que processos de acumulação de capital não existem fora dos contextos geográficos.

Sobre a questão de gênero, diversos são os estudos e os dados que apontam para as desigualdades especialmente entre homens e mulheres. Scott (1995) usa o termo gênero para designar as relações sociais entre sexo, negando explicações biológicas e indicando construções culturais presentes na sociedade. O termo é importante para entender a desigualdade, pois, como mostram Hirata e Kergoat (2007), Carrasco (2015), Federici (2017), Gibb e Oliveira (2015), a divisão sexual do trabalho relega às mulheres os trabalhos ligados ao cuidado, remunerados ou não. No entanto, esses trabalhos são, em geral, desvalorizados socialmente, o que traz diversos empecilhos para as mulheres.

Já quanto à questão de cor/raça ou etnia, em geral as populações brancas no mundo possuem indicadores socioeconômicos melhores que os dos outros grupos. Isso não acontece devido a uma superioridade dessas populações, mas por questões históricas e sociais que permitiram que elas dominassem extensas faixas do globo, subjugando outros povos (se apropriando dos excedentes em seus países de origem, no caso do norte global) e/ou se tornando as elites locais entre os povos dominados (no caso de colônias). $\mathrm{Na}$ arte e na cultura, ainda persistem estereótipos do branco como bom, bonito e puro, enquanto outros fenótipos são preteridos como incapazes, sujos e feios, o que contribui para a reprodução das desigualdades.

Dessa forma, a interdependência desses conceitos importa. Além dela, também deve ser considerada a não hierarquização das formas de opressão (sexo, de cor/raça, de classe, regional), que levam a uma “[...] acumulação histórica de exclusões” (PIRES, 2017, p. 8).

\section{Desigualdade como elemento estruturante da sociedade brasileira}

Pochmann (2014) retoma o percurso histórico da formação dos intocáveis no Brasil, que gerou uma sociedade de extrema desigualdade, possível somente pela combinação do preconceito racial, da exclusão quanto a direitos sociais, do passado colonial/imperial e republicano com a estrutura produtiva que privilegia poucos. A condição de intocável referia-se fundamentalmente ao exercício de atividades ocupacionais de uso informal, sem qualquer direito social ou trabalhista, por vezes oferecendo-se às ocupações servis 
(POCHMANN, 2014). A desigualdade é definida no livro como um projeto deliberado, a fim de manter a concentração do poder econômico e social.

O autor também aponta que a centralidade do trabalho foi a referência original para a adoção de termos como vadios, vagabundos, indolentes e preguiçosos desde a colonização portuguesa (POCHMANN, 2014). Assim, mestiços, índios e negros em situação considerada fora do trabalho passaram a ser enquadrados pela apatia à labuta, como justificativa, inclusive, para a dissociação de direitos e difusão da miséria, tornando as próprias vítimas do processo de exclusão responsáveis pelo quadro generalizado de marginalidade social. Esses, alijados de direitos sociais, foram preteridos em relação aos brancos.

Na mesma linha, Darcy Ribeiro (2006) retoma como a história do Brasil é marcada por conflitos e pela subjugação de índios e negros desde a invasão portuguesa. Segundo Ribeiro (2006), nenhum povo que tivesse uma história de exploração, tortura e desvalorização da vida humana (em especial negra e indígena) sairia sem marcas. De fato, o Brasil foi o último país da América Latina a abolir a escravidão e tal medida foi tomada sem que os ex-escravos tivessem algum tipo de compensação, de forma que eles e seus descendentes fossem relegados a pré-condições diferentes em relação aos brancos. A população negra também apresenta índices mais baixos de representação na política institucional (CAMPOS; MACHADO, 2016), no cinema (CANDIDO et al., 2014), na administração pública (ESCOLA NACIONAL DE ADMINISTRAÇÃO PÚBLICA, 2004) e no acesso à educação (CAMPOS; STORNI; FERES JR, 2014). Valentim e Pinheiro (2015) defendem que o mito de que o Brasil é uma democracia racial esconde um ciclo acumulativo de desvantagens para a população negra e abismos que separam os estratos sociais no Brasil. Ainda, esse mito dissolve conflitos que poderiam transpô-lo, pois se solidifica em uma forma de viver que separa ricos dos pobres.

A Comissão Econômica para a América Latina a Caribe (2016) também mostra que indígenas e negros são muito representativos na população em situação de pobreza/pobreza extrema na América Latina, fato agravado pela transmissão intergeracional das condições em que se encontram e pela invisibilidade estatística desses grupos. O relatório mostra que, apesar da queda da pobreza/pobreza extrema na região, esses grupos continuam com grande vulnerabilidade à pobreza. Indígenas e negros também apresentam menor escolaridade e maior mortalidade infantil, por exemplo. Ainda, o cruzamento das categorias de gênero e etnia/raça mostra populações mais vulneráveis, como as mulheres indígenas ou mulheres negras.

A questão de gênero também é importante na análise da desigualdade ${ }^{2}$. Ainda hoje, as mulheres apresentam renda mais baixa que os homens no Brasil e são identificadas com ocupações ou atividades socialmente desvalorizadas, como as relacionadas ao cuidado e

\footnotetext{
${ }^{2}$ Segundo o indicador de Gender Parity em TBM da Unesco de 2015, o Brasil apresentava um valor de TBM feminina/TBM masculina de 1,4. Para comparação, o valor desse índice para a Argentina no mesmo ano foi de 1,62, da Colômbia de 1,16. Da Índia foi de 0,99.
}

Argum., Vitória, v. 11, n. 3, p. 171-185, set./dez. 2019. | ISSN 2176-9575 
limpeza3. Isso ocorre apesar de as mulheres apresentarem melhores indicadores educacionais que os homens, ou seja, o acesso à educação não foi capaz de alterar essa dinâmica social de desigualdade de gênero no Brasil, pois quanto maior a escolaridade, maior é a diferença salarial entre homens e mulheres no Brasil (TEIXEIRA, 2013).

Além disso, as mulheres que combinam o trabalho doméstico não remunerado e o remunerado no mercado enfrentam uma jornada mais dura (GIBB; OLIVEIRA, 2015; TEIXEIRA, 2013). Os dados mostram ainda que tal questão afeta as mulheres não somente quando adultas, mas desde a infância. Além disso, muitas idosas nunca se aposentam dessas responsabilidades de forma que, na velhice, em vez de serem objeto de cuidado, passam a ser cuidadoras de outros dependentes, como netos, cônjuges ou outros idosos. Porém, especialmente quando se analisam os critérios de gênero e cor/raça juntamente, percebe-se que as mulheres negras no Brasil apresentam indicadores socioeconômicos muito piores que os dos homens brancos.

Também é gritante no Brasil a desigualdade regional, seja ela entre as regiões do Brasil, segundo o Instituto Brasileiro de Geografia e Estatística (IBGE) (considerando que o Norte e o Nordeste ainda apresentam piores indicadores socioeconômicos que o Sul, Sudeste e Centro-Oeste), ou entre o campo e a cidade (há piores índices socioeconômicos no campo do que na cidade). Pochmann (2015) aponta que a hierarquização inter-regional estabelecida no Brasil é, em um primeiro momento, fruto do colonialismo. Entretanto, as relações entre as diferentes regiões do Brasil expressam um tipo de colonialismo interno, com uma correlação entre a concentração econômica e o poder político e administrativo.

Todos esses aspectos se combinam para dar ao Brasil o título de um dos países mais desiguais do mundo, com desigualdades em termos de renda e em termos de acesso a direitos sociais: para muitos brasileiros, o artigo 6o da Constituição Federal, em que se lê que "[...] são direitos sociais a educação, a saúde, a alimentação, o trabalho, a moradia, o transporte, o lazer, a segurança, a previdência social, a proteção à maternidade e à infância, a assistência aos desamparados" (BRASIL, 1988, não paginado), ainda está só no papel.

\section{Início do século XXI: o Brasil na contramão mundial?}

Antunes (2011), Pochmann (2015), Piketty (2015) e Milanovic (2016) apontam que há uma tendência de aumento das desigualdades no mundo desde os anos 80 , que se acentua a partir da crise financeira internacional de 2008. Em contraste com o período do pósguerra (1945-1975), quando ocorreu uma redução da desigualdade nos países ditos desenvolvidos, durante a adoção do chamado Welfare State (ESPING-ANDERSEN, 1991), a crise dos anos 1970, a ascensão do neoliberalismo e a III Revolução Industrial, os rumos da estruturação social foram alterados e levaram a uma retomada do movimento de concentração da riqueza e da renda dentro dos países (FMI, 2017; OCAMPO, 2017;

\footnotetext{
3 No caso das mulheres negras, a associação a serviços ligados a cuidado e limpeza é ainda maior, como herança da escravidão, que lhes relegou esse papel social, tal como discute Davis (2016) para o caso dos Estados Unidos.
} 
OLIVEIRA, 2013). Hoje a maioria da população mundial vive em países onde a desigualdade tem aumentado (JAYADEV; LAHOTI; REDDY, 20154).

\begin{abstract}
Com a crise, reapareceram as condições para que o liberalismo voltasse a ser dominante, o que fez com que o Estado restringisse sua atuação na economia e gerasse menos empregos, o que piorou bastante as condições do mercado de trabalho. Concomitantemente, a III Revolução Industrial reduziu radicalmente a necessidade de trabalhadores, tanto na produção direta de bens como nos serviços associados à produção, graças à introdução do computador. Ou seja, num mundo em que os trabalhos da agricultura, da indústria e dos serviços produtivos eram reduzidos, também o Estado diminuía as oportunidades de emprego (ANTUNES, 2011, p. 2-3).
\end{abstract}

Piketty (2014) analisa outras duas tendências relacionadas à desregulamentação financeira, ampliada desde então, que explicariam o aumento da concentração da renda após 1970: i) o abismo entre as rendas do trabalho se expandiu, de forma que os rendimentos dos altos executivos se distanciaram cada vez mais dos do restante da população; ii) a taxa de remuneração do capital (sob a forma de lucros, dividendos, juros, aluguéis, entre outros) acendeu significativamente mais que a de crescimento da economia como um todo, de forma que a riqueza herdada se expandisse mais que a renda e a produção. Por outro lado, Milanovic (2016) explica que a renda dos quintis médios no mundo (devido especialmente ao crescimento da Ásia) e do $1 \%$ mais rico no mundo foi a que mais aumentou em termos percentuais de 1988 a 2008. Em termos absolutos, grande parte do aumento da renda mundial de 1988 a 2008 foi absorvida pelos mais ricos (44\% do crescimento da renda total foi apropriado pelos $5 \%$ mais ricos e quase $20 \%$ pelo $1 \%$ mais rico, enquanto cada $5 \%$ da chamada classe média global se apropriou de 2 a $4 \%$ do aumento da renda nesse período), contribuindo para o que o autor chama de plutocracia global.

Por causa desse fenômeno, a discussão sobre a desigualdade passou a atrair mais atenção dos economistas em todo o mundo, em especial pelo seu efeito deletério no crescimento econômico e pela crise de 2008. Esse debate também envolveu a política e a economia brasileiras, já que o Brasil parecia estar em uma espécie de contramão, reduzindo as desigualdades no país, enquanto a desigualdade crescia, em especial entre os países do Norte do globo. Esse argumento foi muito frequente em estudos nacionais e internacionais até o ano de 2014 .

Tal constatação pode ser percebida a partir de pesquisas e medidores. Por exemplo, entre 1988 e 2008, o coeficiente de Gini aumentou em 58 países, ou seja, sete de cada dez pessoas residiam em lugares cuja concentração da renda havia se ampliado no período recente. Já, segundo o Departamento Intersindical de Estatística e Estudos SócioEconômicos (2014), entre 2002 e 2012, o coeficiente de Gini diminuiu de o,59 para 0,53 no Brasil, enquanto, nesse mesmo intervalo de tempo, a razão entre a renda dos $10 \%$ mais ricos e a dos $40 \%$ mais pobres declinou de $22,2 \%$ para $15,4 \%$. No entanto, o Departamento Intersindical de Estatística e Estudos Sócio-Econômicos (2017) pondera que, apesar da melhora, o país continuava apresentando altos níveis de desigualdade.

Outro estudo que coloca o Brasil na contramão das tendências mundiais de aumento das desigualdades é o da Oxfam (2014), que mostrou que, desde o início da crise

Argum., Vitória, v. 11, n. 3, p. 171-185, set./dez. 2019. | ISSN 2176-9575 
financeira internacional, o número de bilionários no mundo mais que dobrou e 7 entre 10 pessoas vivem em países onde a distância entre ricos e pobres é maior do que era há 30 anos. Ele também revela que houve uma queda da participação da renda do trabalho no PIB para um amplo conjunto de países. Já o Brasil, apesar de seus históricos e graves problemas de desigualdade social, é citado nessa pesquisa como exceção, inclusive com a utilização do termo Brazilian Dream. Entre os Brics, no início do século XXI, o relatório relembra que o Brasil foi o único a reduzir a desigualdade.

De fato, alguns autores caracterizam o início do século XXI, ou, de forma semelhante, o período pós 1988, como um tempo que segue na contramão da história do Brasil (FAGNANI, 2017). A sociedade brasileira, fundada na desigualdade e na exclusão, parece ter vivido um momento em que se institucionalizou o combate às desigualdades e se garantiram direitos. Isso é marcado pela Constituição Federal de 1988 (CF 88) e sua institucionalidade e pela ampliação dos gastos sociais e a redução das desigualdades no início do século XXI.

Campello (2017) afirma que, aliada à queda da pobreza e da miséria sem precedentes da história brasileira, nesse período

[...] [é] inegável a redução da desigualdade de renda usando os dados da Pnad. O crescimento real da renda do conjunto da população chegou a $38 \%$ e foi ainda mais acentuado entre os mais pobres. A renda dos $20 \%$ mais pobres cresceu quase 4 vezes mais rápido que a dos $20 \%$ mais ricos. A ampliação acima da inflação ocorreu para todas as faixas de renda, apesar dos efeitos da crise econômica que já se fizeram sentir a partir de 2012 (CAMPELLO, 2017, p. 63).

A pesquisadora explicita a correlação no Brasil entre desigualdade e pobreza baseandose no Î́ndice de pobreza crônica multidimensional desenvolvido pelo Banco Mundial. O índice incorpora indicadores de renda monetária e não monetária e define que pobreza crônica multidimensional afeta famílias com renda abaixo da linha pobreza com três ou mais privações dentre as sete dimensões consideradas estratégicas, como: educação (adolescentes e jovens de 15 a 17 anos no ensino médio, jovens de 18 a 24 anos no ensino superior e chefes de família com ensino fundamental completo), serviços de infraestrutura (tais como energia elétrica, água de qualidade e escoamento sanitário), habitação, bens de consumo (como geladeira ou freezer, máquina de lavar, celular e computador com internet), igualdade racial, saúde e renda. Campello (2017) analisa, a partir de dados da PNAD de 2002 a 2015, como, no Brasil, o acesso a direitos básicos melhorou e o hiato entre os $5 \%$ e os $20 \%$ mais pobres e o resto da população reduziu. Ela mostra que a desigualdade no acesso a direitos sociais de 2002 a 2015 diminuiu, trazendo uma perspectiva mais ampla para o conceito de desigualdade, geralmente tratado como uma questão de renda. Para um exemplo bem brasileiro: ter uma cisterna no semiárido do Nordeste, segundo a autora, marca a diferença entre passar fome ou não, mas tal bem não é contabilizado nas estatísticas de patrimônio e renda.

Segundo a mesma publicação (CAMPELLO, 2017), em 2002 os pobres crônicos no Brasil somavam 9,3\% da população, enquanto em 2015 o percentual foi reduzido para o índice de $1 \%$. Logo, a pobreza crônica multidimensional caiu mais acentuadamente do que a pobreza exclusivamente pela renda, refletindo o esforço de superar privações históricas 
e estruturais, como a educação dos pais, acesso à água de qualidade, saneamento, energia e acesso a bens de consumo. Assim, afirma a autora que, “[...] em todas essas perspectivas, o Brasil de 2015 é muito menos desigual que o Brasil de 2002 [...]" (CAMPELLO, 2017, p. 70), inclusive considerando-se esse índice em relação a cor/raça, população urbana e rural e regiões do Brasil.

Já Pochmann (2015) calcula, a partir de dados do Censo, a variação acumulada dos decis de rendimento médio da distribuição da renda da população economicamente ativa no início do século XXI. O autor mostra que a renda, durante essa década, subiu em média $25,5 \%$, com um crescimento maior nos décimos mais pobres: o crescimento do primeiro décimo foi de 59\%; do segundo (o maior) de 75,5\%; o terceiro de 57,5 e daí segue uma trajetória quase sempre declinante, até chegar ao último décimo (o mais rico), em que a renda média cresceu 19,9\%. Assim, a razão entre o rendimento médio do décimo mais rico e o rendimento médio do décimo mais pobre caiu de 53,2 em 2000 para 39,4 em 2010, indicando melhora na distribuição de renda, de acordo com os dados do Censo.

Todavia, nem todos os pesquisadores concordam que tenha ocorrido uma queda da desigualdade no início do século XXI. Fagnani (2017) chama esse debate de falsa controvérsia e afirma que houve sim queda da desigualdade da renda do trabalho, em decorrência, segundo ele "[...] do crescimento da economia e suas consequências no mercado de trabalho e na potencialização dos gastos sociais e dos efeitos redistributivos do Estado Social fundado em 1988" (FAGNANI, 2017, p. 3). O autor pondera, porém, que tais transformações não vieram acompanhadas por mudanças estruturais necessárias para aprofundar e manter esses progressos, tais como uma reforma tributária que corrigisse o caráter regressivo do sistema tributário brasileiro.

Para Campello (2017), Fagnani (2017) e Pochmann (2015), a queda da desigualdade de renda no Brasil se deve a uma combinação das melhorias observadas no mercado de trabalho (como aumento do emprego assalariado, da formalização, dos rendimentos especialmente os mais baixos - etc.), dos programas de transferência de renda, como o Programa Bolsa Família (PBF), e do desenvolvimento de uma rede de proteção social mais efetiva com o crescimento econômico do país, apesar da crise econômica mundial. $\mathrm{O}$ investimento social também teve um importante papel, apesar de ainda não ser suficiente para reparar a exclusão (FAGNANI, 2017). Segundo o autor, gastos com educação pública reduziram o Gini em 1,1\%; com saúde pública em 1,5\%; com o Bolsa Família em 2,2\% e com outras transferências em 2,3\%.

No entanto, trabalhos que utilizam dados da Receita Federal têm questionado a dimensão da queda da desigualdade no Brasil no início do século XXI. É importante salientar que é muito recente a utilização desses dados para estudos sobre a riqueza e a desigualdade no país.

Pochmann (2017) relembra que a maioria das pesquisas sobre esse tema se centraram em noções estritamente matemáticas da desigualdade, utilizando-se das fontes oficiais de pesquisa disponíveis (em sua grande maioria, por sua vez, baseadas em pesquisas domiciliares, que bem captam a renda do trabalho, mas nem tanto a renda oriunda do capital). Assim, “[...] o sentido das intervenções governamentais desde a retomada do

Argum., Vitória, v. 11, n. 3, p. 171-185, set./dez. 2019. | ISSN 2176-9575 
regime democrático em 1985 concentrou-se na busca da equidade nos rendimentos do trabalho, liberando, contudo, as rendas do capital" (POCHMANN, 2017, p. 32). Isso aconteceu em parte pela dificuldade de realizar uma reforma tributária mais progressiva, mas também em parte porque a discussão sobre desigualdade está condicionada aos instrumentos que se dispõem para medi-la.

A partir das informações de declaração do Imposto de Renda, que passaram a estar disponíveis mais recentemente e que melhor expressam a renda do capital, é possível verificar que, apesar dos avanços no início do século XXI, a desigualdade para detentores de patrimônio permaneceu elevada no Brasil4. Por isso, Pochmann (2017) insiste na importância dos estudos e das metodologias aplicadas para entender a desigualdade: aqueles aspectos ressaltados ou escondidos pelas metodologias ajudam a moldar a opinião pública e os instrumentos de intervenção. Alguns estudos podem até mesmo levar à legitimação da desigualdade, caso apontem para a adoção de políticas públicas insuficientes ou incapazes de alterar a sua realidade. Ou, nas palavras do autor,

\begin{abstract}
A experiência dos governos dos anos 2000 comprova inegável resultado em termos da redução na desigualdade daqueles dependentes do rendimento do trabalho e das transferências públicas. Era essa a manifestação da desigualdade que a maioria dos estudos especializados se encontrava concentrada até o início do século XXI. A partir disso, pode-se constatar que à medida que os estudos adotem conceitos multidimensionais das iniquidades e que consigam incorporar o conjunto dos rendimentos da população, como os dos proprietários, a orientação das políticas públicas tende a recair sobre as desigualdades do capital. Isso, é claro, pelos governos comprometidos com o enfrentamento efetivo da desigualdade, não a sua naturalização ou mesmo legitimação (POCHMANN, 2017, p. 33).
\end{abstract}

Por exemplo, em um conhecido estudo baseado na metodologia de Thomas Piketty, Morgan (2017) defende que a desigualdade de renda no Brasil é ainda mais resistente a mudanças do que se imagina. Ele acrescenta que as tendências quanto à desigualdade no Brasil poderiam não ter sido tão diferentes assim do resto do mundo (contrapondose em parte, portanto, à visão de que, no início do século XXI, o Brasil teria estado na contramão do mundo em termos de redução das desigualdades). Segundo a sua metodologia, que combina as bases das Contas Nacionais, Pnad e Receita Federal para corrigir as omissões de cada uma das estimativas e medir a desigualdade de mercado (antes de tributação e transferências), a desigualdade de renda é maior do que se pensa e teria aumentado no início do século XXI: o $1 \%$ mais rico tinha $25 \%$ da renda em 2001 , que passou a $28 \%$ em 2015 , capturando $43 \%$ do crescimento da renda nesse período; os $10 \%$ mais ricos passaram de $54 \%$ para $55 \%$ e capturaram $61 \%$ do crescimento total; já os $50 \%$ mais pobres passaram de $11 \%$ para $12 \%$ (14\% contabilizando o efeito do PBF), capturando $18 \%$ do crescimento total, mas em ritmo mais alto que os $10 \%$ mais ricos; no entanto, os $40 \%$ do meio caíram de $34 \%$ para $32 \%$ da fatia da renda nacional. Assim, de acordo com o estudo do autor, a desigualdade caiu entre os $90 \%$ mais pobres, mas houve

4 Uma questão importante é que, desde quando os dados do Imposto de Renda de Pessoa Física (IRPF) se tornaram mais acessíveis, tem ganhado peso a discussão sobre a taxação de lucros e dividendos no Brasil, isentos em geral de IRPF desde 1995. Em diversos campos do espectro político, tem sido defendido o retorno de sua taxação, com a justificativa de garantir maior progressividade do IRPF, dado que proporcionalmente os cidadãos de maior renda recebem mais rendimentos em forma de lucros e dividendos, reduzindo, assim, sua alíquota efetiva de IRPF. 
maior concentração em prol dos mais ricos: a desigualdade da renda do trabalho caiu, mas não foi suficiente para se contrapor à concentração de capital.

Voltamos, então, à discussão sobre metodologias para medição da desigualdade e como elas influenciam na criação de políticas públicas para solucionar os problemas conhecidos. A partir do momento em que se tornam mais usuais estudos que utilizem fontes de dados que captem com mais precisão a renda e a riqueza dos mais ricos, é possível pressionar para que haja a adoção de políticas que possam dirimir esse problema.

Por outro lado, medidas multidimensionais, como a desenvolvida por Campello (2017), mostram que houve queda na desigualdade durante os anos 2000, se medida a diferença de acesso a direitos sociais de acordo com a renda dos brasileiros. Inspirada por essa metodologia, Oliveira (2019), em um trabalho que discute a inclusão social na educação superior no início do século XXI, mostra que houve um aumento significativo desse dado de acordo com renda, raça/cor e regional, pelo menos até 2015. No Gráfico 1, por exemplo, de 2001 a 2015, percebe-se um aumento da porcentagem de estudantes de graduação com renda per capita de até 2 salários-mínimos (SM), aproximando-se da porcentagem desse grupo na população brasileira.

Gráfico 1 - Percentual de estudantes de graduação e da população brasileira com renda de até 2 SM per capita, \% (2001-2015).

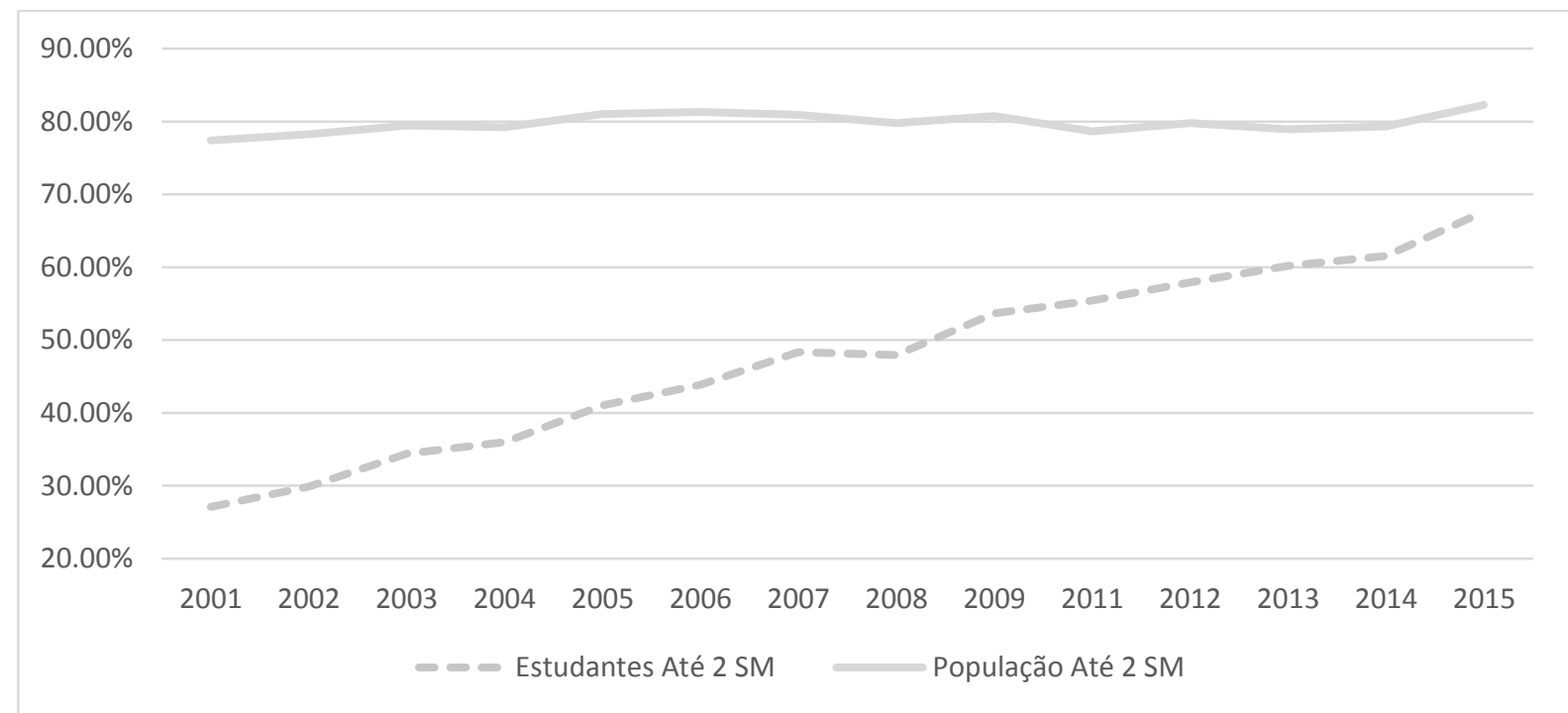

Fonte: Elaboração própria a partir de PNAD/SPSS.

Já o Gráfico 2 mostra que, enquanto o percentual de negros na população brasileira sobe, entre 2001 e 2015, o percentual de estudantes de educação superior negros cresce muito mais, aproximando os dois valores ao longo do tempo: em termos raciais, o perfil dos estudantes se aproximou mais, nesse período, ao da população brasileira.

Argum., Vitória, v. 11, n. 3, p. 171-185, set./dez. 2019. | ISSN 2176-9575 
Gráfico 2 - Percentual de negros entre estudantes de graduação e na população brasileira (20o12015)

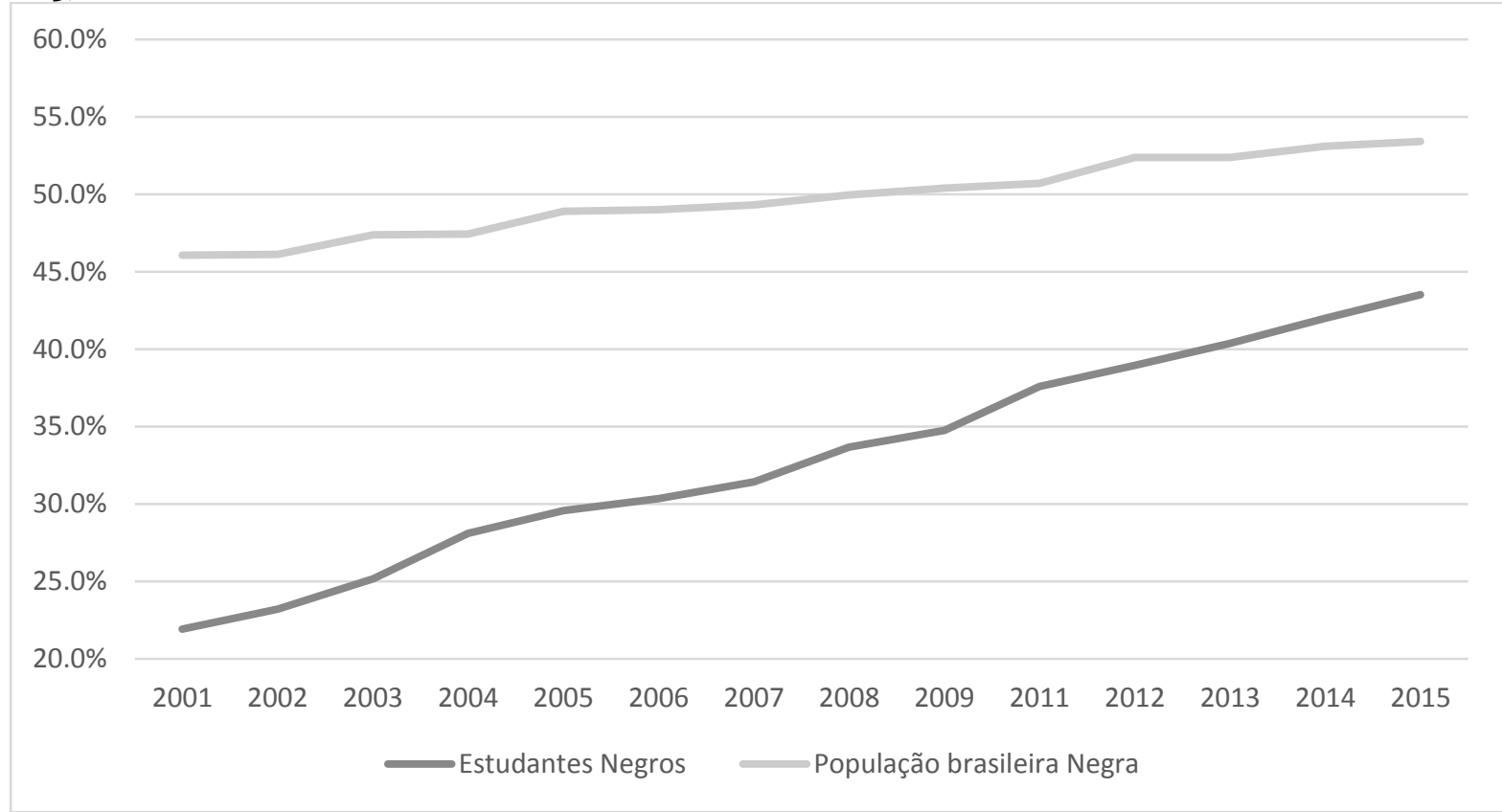

Fonte: Elaboração própria a partir de PNAD/SPSS.

A partir de 2015, no entanto, com a adoção da austeridade fiscal e a crise do mercado de trabalho, que advém da mudança na política econômica, o ciclo de redução das desigualdades pode estar em risco. Um problema para a medição da desigualdade, que se coloca justo neste ano, é a descontinuidade da Pesquisa Nacional por Amostra de Domicílios (PNAD), que foi substituída pela PNAD Contínua. Como não seguem diretamente a mesma metodologia, ambas não são diretamente comparáveis e causam um gap na série temporal, se o objetivo é fazer estudos sobre a concentração de renda no Brasil recente.

\section{Considerações finais}

Neste artigo, discutiram-se as diversas visões sobre a redução de desigualdades no Brasil do início do século XXI. Se não há consenso entre os autores - devido a diferentes metodologias adotadas para medir o fenômeno - quanto à queda da desigualdade de renda no período, a literatura indica que há uma queda da desigualdade relativa ao acesso de direitos sociais, sendo Campello (2017) um importante expoente dessa vertente. Segundo ela, o país teria sim caminhado na contramão mundial. Por outro lado, alguns autores, como Morgan (2017), enfatizam que a tendência da concentração da renda no Brasil não diferiu do encontrado em países do capitalismo central nos anos recentes, portanto o país não teria estado tanto na contramão do aumento da desigualdade como mostram as medidas baseadas em pesquisas domiciliares.

No entanto, o processo que se segue a 2015, após a mudança na política econômica que leva ao corte de orçamento para a área social e à crise no mercado de trabalho, a redução das desigualdades - até mesmo no acesso a direitos - parece estar em risco, colocando em questão a real profundidade do processo vivido durante o início dos anos 2000. 


\section{Referências}

ANTUNES, D. J. N. Capitalismo e desigualdade. 2011. Tese (Doutorado em Ciências Econômicas)- Universidade Estadual de Campinas, Campinas, 2011. BRASIL. Constituição Federal 1988. 1988. Disponível em: https://goo.gl/kB3NGH. Acesso em: 21 nov. 2018.

CAMPELLO, T. Faces da desigualdade no Brasil: um olhar sobre os que ficam para trás. Brasília (DF): Clacso; Flacso; Agenda Igualdade, 2017.

CAMPOS, L. A.; MACHADO, C. A cor e o sexo da política: candidatos e candidatas nas eleições municipais de 2016. Rio de Janeiro: IESP-UERJ, 2016. (Textos para discussão GEMAA).

CAMPOS, L. A.; STORNI, T.; FERES JR., J. A cor do ENEM 2012: comparações entre o desempenho de brancos, pardos e pretos. Rio de Janeiro: IESP-UERJ, 2014. (Textos para discussão GEMAA, n. 8).

CANDIDO, M. R. et al. "A cara do cinema nacional”: gênero e cor dos atores, diretores e roteiristas dos filmes brasileiros (2002-2012). Rio de Janeiro: IESP-UERJ, 2014. (Textos para discussão GEMAA, n. 8).

CARNEIRO, R. Velhos e novos desenvolvimentismos. Economia e Sociedade, Campinas, v. 21, n. 4, dez. 2012 [especial]. Disponível em:

https://periodicos.sbu.unicamp.br/ojs/index.php/ecos/article/view/8642255. Acesso em: 21 jan. 2019.

CARRASCO, C. Con voz propia: la economía feminista como apuesta teórica y política. Revista de Economía Crítica, Madrid: La oveja roja, n. 19, primer semestre 2015.

COMISSÃO ECONÔMICA PARA A AMÉRICA LATINA E CARIBE. CEPAL. Desarrollo social inclusivo: una nueva generación de políticas para superar la pobreza y reducir la desigualdad en América Latina y el Caribe. Editorial CEPAL, Santiago: Naciones Unidas, enero, 2016. Disponível em: http://www.cepal.org/es/node/34596. Acesso em: 29 dez. 2018.

DAVIS, A. Mulheres, raça e classe. Tradução Heci Regina Candiani. São Paulo: Boitempo, 2016.

DEPARTAMENTO INTERSINDICAL DE ESTATÍSTICA E ESTUDOS SÓCIOECONÔMICOS. Política de valorização do salário mínimo: depois de 20 anos, reajuste fica abaixo da inflação (INPC). São Paulo, jan. 2017. (Nota técnica, n. 166). Disponível em: https://goo.gl/PCJPgV. Acesso em: 19 dez. 2018.

DEPARTAMENTO INTERSINDICAL DE ESTATÍSTICA E ESTUDOS SÓCIOECONÔMICOS. $\mathbf{O}$ avanço das desigualdades nos países desenvolvidos: lições para 
o Brasil. São Paulo, jul. 2014. (Nota técnica, n. 138). Disponível em: https://goo.gl/JUxdrW. Acesso em: 20 nov. 2018.

DWECK, E.; SILVEIRA, F. G.; ROSSI, P. Austeridade e desigualdade social no Brasil. In: ROSSI, P.; DWECK, E.; OLIVEIRA, A. L. M. (org). Economia para Poucos: impactos sociais da austeridade e alternativas para o Brasil. São Paulo: Editora Autonomia Literária, 2018.

\section{ESCOLA NACIONAL DE ADMINISTRAÇÃO PÚBLICA. Gênero, raça e} competências de direção no Serviço Público Federal. Brasília (DF), 2004.

ESPING-ANDERSEN, G. As três economias políticas do Welfare State. Lua nova, São Paulo, n. 24. set. 1991. Disponível em: https://goo.gl/ShGwGS. Acesso em: 10 set. 2014.

FAGNANI, E. Projeto de país, desigualdade e poder da desinformação. In: FUNDAÇÃO PERSEU ABRAMO. Qual é o Projeto de Desenvolvimento para o Brasil do Futuro?. São Paulo: 1. nov. 2017. p. 4-20.

FEDERICI, S. Notas sobre gênero em 'O Capital' de Marx. Revista Democracia Socialista, São Paulo: Associação Caetés, n. 6, p. 83-111, out. 2017.

FMI. IMF Fiscal Monitor: Tackling Inequality, October 2017. Washington, D.C., 2017. Disponível em: https://www.imf.org/en/Publications/FM/Issues/2017/10/05/fiscalmonitor-october-2017 . Acesso em: 28 dez. 2019.

GIBB, L. S. F.; OLIVEIRA, A. L. M. A desigualdade na distribuição do trabalho total no Brasil: a quem favorece?. Revista Pesquisa \& Debate, São Paulo, v. 26, n. 2, p. 87-104, set. 2015 .

HARVEY, D. O enigma do capital e as crises do capitalismo. São Paulo: Boitempo, 2011.

HIRATA, H.; KERGOAT, D. Novas Configurações da Divisão Sexual do Trabalho. Cadernos de Pesquisa, São Paulo, v. 37, n. 132, p. 595-609, set./dez. 2007.

JAYADEV, A.; LAHOTI, R.; REDDY, S. Who Got What, Then and Now? A Fifty Year Overview from the Global Consumption and Income Project. SSRN, New York, 5 maio 2015. Disponível em: https://papers.ssrn.com/sol3/papers.cfm?abstract_id=2602268 . Acesso em: 10 jan. 2017.

MILANOVIC, B. Global inequality: a new approach for the age of globalization. London: Press of Harvard University, 2016.

MORENO, L. Equity, equality and equivalence: a contribution in search for conceptual definitions and a comparative methodology. Revista Española de Educación

Comparada, Madrid, n. 13, p. 319-340, 2007. 
MORGAN, M. Falling Inequality beneath Extreme and Persistent Concentration: New Evidence for Brazil Combining National Accounts, Surveys and Fiscal Data, 2001-2015. Wid.World Working Paper Series, n. 12, ago. 2017.

OCAMPO, J. A. Why reducing inequality must be a global effort. International Politics and Society, 31 out. 2017. Disponível em: https://goo.gl/UrGniR. Acesso em: 28 jan. 2018.

OLIVEIRA, A. L. M. Regulação estatal das relações de trabalho no capitalismo contemporâneo: uma crítica ao discurso da flexibilização e desregulamentação. 2013. Dissertação (Mestrado em Economia Social)- Universidade Estadual de Campinas, Campinas, 2013.

OLIVEIRA, A. L. M. Educação Superior brasileira no início do século XXI: inclusão interrompida?. 2019. Tese (Doutorado em Economia)- Universidade Estadual de Campinas, Campinas, 2019.

OXFAM. Equilibre o jogo!: É hora de acabar com a desigualdade extrema. [S.l.]: Oxfam, 2014. Disponível em: https://www-cdn.oxfam.org/s3fspublic/file_attachments/cr-even-it-up-extreme-inequality-291014-summ-pt.pdf. Acesso em: 20 nov. 2018.

OXFAM. País Estagnado: um retrato das desigualdades brasileiras. [S.l.]: Oxfam, 2018. Disponível em:

https://www.oxfam.org.br/sites/default/files/arquivos/relatorio_desigualdade_2018_pa is_estagnado_digital.pdf. Acesso em: 24 jan. 2019.

PIKETTY, T. A economia da desigualdade. Rio de Janeiro: Intrínseca, 2015.

PIKETTY, T. O capital no século XXI. Rio de Janeiro: Intrínseca, 2014.

PIRES, R. R. C. Implementando desigualdades? Introdução a uma agenda de pesquisa sobre agentes estatais, representações sociais e (re)produção de desigualdades.

Boletim de Análise Político-Institucional, Rio de Janeiro: IPEA, out. 2017.

POCHMANN, M. Desigualdade brasileira no início do século XXI: o que há de novo? A grande sociedade - qual é o projeto de desenvolvimento para o Brasil do futuro?. São Paulo: Fundação Perseu Abramo, 2017.

POCHMANN, M. Desigualdade econômica no Brasil. São Paulo: Ideias \& Letras, 2015.

POCHMANN, M. A vez dos intocáveis no Brasil. São Paulo: Fundação Perseu Abramo, 2014.

RIBEIRO, D. O povo brasileiro: a formação e o sentido do Brasil. São Paulo: Companhia das Letras, 2006. 
ROSSI, P.; DWECK, E.; OLIVEIRA, A. L. M. (org.) Economia Para Poucos: impactos sociais da austeridade e alternativas para o Brasil. São Paulo: Autonomia Literária, 2018.

SCOTT, J. Gênero: uma categoria útil de análise histórica. Educação \& Realidade, Porto Alegre, v. 20, n. 2, jul./dez. 1995, p. 71-99.

TEIXEIRA, M. O. O mercado de trabalho reitera relações desiguais que se constroem no âmbito das relações econômicas e sociais. In: FUNDAÇÃO PERSEU ABRAMO; FUNDAÇÃO FRIEDRICH EBERT (org.). Classes? Que classes?: Ciclo de debates sobre classes sociais. 1. ed. São Paulo: Fundação Perseu Abramo/Fundação Friedrich Ebert, 2013. p. 105-124.

VALENTIM, S. S.; PINHEIRO, K. L. M. Ações afirmativas de base racial na educação pública brasileira. Educação \&Tecnologia, Belo Horizonte, v. 20, n. 1, p. 11-22, jan./abr. 2015. Disponível em: https://goo.gl/kutYgn. Acesso em: 3 abr. 2018.

\section{Ana Luíza Matos de OLIVEIRA}

Economista e doutora em desenvolvimento econômico, com experiência em universidades brasileiras e estrangeiras. Hoje é professora visitante na Flacso Brasil, é parte da equipe do Brasil Debate e analista da Fundação Perseu Abramo. 